\title{
Problemas éticos na saúde bucal no contexto da Atenção Primária à Saúde
}

| ${ }^{1}$ Doris Gomes, ${ }^{2}$ Elma Lourdes Campos Zoboli, ${ }^{3}$ Mirele Finkler I

Resumo: Diante da ausência de estudos voltados às questôes éticas vivenciadas por profissionais de Saúde Bucal no contexto da Atenção Primária à Saúde (APS) e como primeira etapa de adaptação com validação do Inventário de Problemas Éticos na Atenção Primária à Saúde (IPEAPS) para a saúde bucal, objetiva-se, com esta pesquisa, desvelar os problemas éticos que ocorrem nas relaçóes de trabalho e na produção do cuidado em saúde bucal. Foram realizadas entrevistas com profissionais que atuam no modelo da Estratégia Saúde da Família, no tradicional ou arranjos singulares da APS. Os dados coletados foram qualitativamente analisados à luz da Bioética Clínica Amplificada e de outros referenciais da Bioética Social brasileira. Os resultados evidenciaram 32 problemas éticopolíticos em diferentes âmbitos: acesso e acolhimento, gestão, relações com usuários, intra e interequipes, entre os diferentes níveis da rede e relacionados a processos macroestruturais, ficando pouco nítidos os limites de transformação de problemas cotidianos em problemas éticos. Tais problemas, majoritariamente de caráter técnico, administrativo ou estrutural, envolvendo questôes materiais, financeiras e organizacionais, possuem uma dimensão ética e, também, política, além da deontológica, pois influenciam os modos de viver, trabalhar e produzir cuidado.

> Palavras-chave: odontologia; saúde bucal; atenção primária à saúde; bioética; ética.

\author{
1 Universidade Federal de Santa \\ Catarina. Florianópolis-SC, Brasil \\ (dorisgomesodonto@gmail.com). \\ ORCID: 0000-0003-2445-8318 \\ 2 Escola de Enfermagem, \\ Universidade de São Paulo. \\ São Paulo-SP, Brasil (elmausp@ \\ gmail.com). \\ ORCID: 0000-0002-7324-5389 \\ ${ }^{3}$ Universidade Federal de Santa \\ Catarina. Florianópolis-SC, Brasil \\ (mirellefinkler@yahoo.com.br). \\ ORCID: 0000-0001-5764-9183
}

Recebido em: 29/05/2018 Revisado em: 02/03/2019 Aprovado em: 12/03/2019 


\section{Introdução}

É na Atenção Primária à Saúde (APS) que acontece o primeiro contato do usuário com o Sistema Único de Saúde (SUS), caracterizado pelo encontro intersubjetivo entre profissional/equipe e usuário/comunidade (ZOBOLI, 2010). Sua expansão e qualificação estão relacionadas à reorientação do processo de trabalho, priorizando tecnologias não materiais, desde final dos anos 1990, com: o Programa de Saúde da Família, posteriormente transformado em Estratégia (ESF); a publicação das Diretrizes Curriculares Nacionais (DCN, 2002); a Política Nacional de Humanização (2003); a Política Nacional de Saúde Bucal (PNSB), em 2004 (BRASIL, 2018); e a Política Nacional de Atenção Básica (PNAB, 2006). Busca-se, assim, a consolidação de uma lógica assistencial para além da obrigação de resultados, em defesa dos direitos dos pacientes e da não discriminação (FORTES, 2011), solicitando novo posicionamento ético-político dos trabalhadores.

A inserção de Equipes de Saúde Bucal (ESB) na ESF propóe uma articulação da saúde bucal (SB) com a rede de serviços, voltada à integralidade das açôes (AUSTRAGÉSILO et al., 2015), ampliação e qualificação da atenção especializada (implantação dos Centros de Especialidades Odontológicas - CEO e Laboratórios Regionais de Próteses Dentárias) e viabilização da fluoretação das águas de abastecimento público. Procura-se superar o histórico modelo da profissão odontológica calcado no imaginário liberal-privatista (FRAZÃO; NARVAI, 2014), construindo uma clínica ampliada, multiprofissional e interdisciplinar, centrada na dialogicidade-comunicação entre os sujeitos e nas necessidades epidemiológicas e sociais da população (CAMPOS, 2013).

Mantém-se, no entanto, variados e singulares arranjos de APS, resultado da convivência de diferentes modelos, estruturas, composição de equipes, operacionalização e oferta de serviços. Evidencia-se um quadro nacional disforme que favorece a tradicional descontinuidade na atenção, com hierarquização e fragmentação da rede em pontos isolados e incomunicados (FORTE; PIRES, 2017; COSTA et al., 2014) e conflitos na interpretação do seu funcionamento (SCHERER; SCHERER, 2015; POÇAS et al., 2017). Como o trabalho em saúde foi historicamente reduzido à incorporação de tecnologia material e à hiperespecializaçáo associadas aos processos de estratificação do acesso pelos interesses de mercado, aponta-se a necessidade de uma ressignificaçáo de conhecimentos, valores, responsabilidades e 
fazeres na APS (THUROW; CASTILHOS; COSTA, 2015; AUSTRAGÉSILO et al., 2015; AMORIM; SOUZA, 2010).

Segundo Cangussu, Passos-Soares e Cabral (2016), apesar do expressivo crescimento na oferta de serviços, com quase o dobro de ESB entre 2004-2010 somado à implantação dos $\mathrm{CEO}$, o impacto nos padróes de acesso e efetividade dos serviços ou seu resultado na SB da população brasileira ainda não se mostra significativo, nem se diferencia substancialmente do tipo de cuidado ofertado pelo modelo tradicional, contribuindo pouco para a melhoria dos indicadores epidemiológicos e assistenciais. Um quadro que impóe uma reflexão sobre estratégias de ação voltadas a grupos vulnerados, realidades epidemiológicas com reorientação de futuras ações da PNSB (CANGUSSU; PASSOS-SOARES; CABRAL, 2016) e uma "des-re-construção" da clínica, desde o papel do Cirurgião-dentista (CD), Auxiliar de Saúde Bucal (ASB) e Técnico de Saúde Bucal (TSB) até um novo modo de saber-fazer socialmente comprometido e em equipe.

O Programa para Melhoria do Acesso e da Qualidade da Atenção Básica (PMAQ), desde 2011, entende como atributos desta melhora: acesso, longitudinalidade, integralidade e coordenação, tornando o conceito de "qualidade" relativo e complexo, exigindo redefinições sucessivas e esforços múltiplos voltados ao seu entendimento, na concretude das ações em saúde (POÇAS; FREITAS; DUARTE, 2017). No mesmo sentido, esforça-se por desvelar problemas éticos cotidianos, surgidos nos diferentes arranjos da atenção, e entendidos como aqueles aspectos, questóes ou implicaçóes das práticas em saúde que revelam conflitos morais, não necessariamente dilemas (ZOBOLI; FORTES, 2004). Nos últimos 15 anos, o seu reconhecimento e a produçấo de espaços de debate bioético têm sido possíveis pela construção de um Inventário de Problemas Éticos (IPE-APS) original e oriundo das realidades de trabalho no SUS, em formato de questionário fechado e estruturado, já validado quali e quantitativamente para diversificadas realidades (JUNGES et al., 2014a; 2014b).

Este rol de pesquisas voltado aos problemas éticos na APS, desencadeado pela intersecção prática e epistemológica da Bioética com a Saúde Coletiva (JUNGES; ZOBOLI, 2012; PORTO; GARRAFA, 2011), deu origem ao IPE-APS e a um novo ramo da Bioética Social brasileira: a Bioética Clínica Amplificada. Um referencial teórico-prático fundamentado na Bioética Deliberativa de Diego Gracia e na Ética do Cuidado. Buscando desnaturalizar e dar visibilidade aos problemas éticos cotidianos da APS, diferencia-se da tradição principialista da bioética, predominantemente 
focada na assistência clínico-hospitalar e nos conflitos decorrentes do avanço da biotecnologia (ZOBOLI, 2010). Este estudo constitui-se, entáo, de uma primeira etapa da adaptação e validação do IPE-APS para a SB, levantando os problemas éticos vivenciados nas relações de trabalho e na produção do cuidado pela SB.

\section{Metodologia}

A primeira etapa de adaptação com validação do IPE-APS para a SB consistiu deste levantamento de problemas éticos, que serviu como base para o entendimento e descrição destes problemas e voltado à comparação e equivalência de itens, semântica e de conteúdo com o IPE-APS original. Posteriormente, o IPE-APS adaptado à SB será validado por meio da técnica de Delphi, para melhora da compreensibilidade e, finalmente, será submetido a uma analise fatorial após aplicação do instrumento em uma amostra representativa de profissionais da SB.

Esta pesquisa descritiva foi de abordagem qualitativa, feita na regiáo metropolitana de Florianópolis-SC, englobando os quatro maiores municípios: Florianópolis, Palhoça, Biguaçu e São José. Destes, Florianópolis é o único que incorpora o trabalho do TSB e tem todos os trabalhadores da SB inseridos na ESF - o município de São José não aderiu à Estratégia e os de Palhoça e Biguaçu aderiram parcialmente. Iniciou-se com a autorização da Secretaria Municipal de Saúde de todos os envolvidos e a aprovaçáo do projeto pelo Comitê de Ética em Pesquisa (CAAE 60739716.1.0000.0121). A coleta dos dados foi conduzida entre dezembro de $2016 \mathrm{e}$ 2017 pela pesquisadora principal, que é cirurgiã-dentista, profissional há 19 anos da APS, em um município incluído, doutora em Filosofia da Enfermagem e doutoranda em Odontologia, com experiência em metodologias qualitativas de pesquisa. As entrevistas semiestruturadas foram guiadas por um roteiro previamente elaborado a partir dos problemas éticos do IPE-APS, e gravadas. A seleção dos participantes deuse a partir da indicação das coordenações de SB dos municípios, seguindo o método bola de neve, no qual os participantes vão sendo definidos ao longo do estudo por indicação deles mesmos, até atingir o critério de saturação ou repetição dos dados.

Foram entrevistados 14 profissionais da APS (12 mulheres e 2 homens), dos quais nove atuam no modelo ESF (4 CD, 2 TSB, 3 ASB) e 5, no modelo tradicional (3 CD e $2 \mathrm{ASB}$ ). Os participantes foram convidados via contato telefônico ou pessoalmente, sem nenhuma recusa, manifestando consentimento livre e esclarecido 
após conversa acerca dos objetivos e procedimentos de pesquisa. Tinham idades variadas e atuavam a mais de um ano na função (apenas 1 ASB trabalhava a menos tempo). Cada profissional foi entrevistado uma única vez, em ambiente reservado, com duração média de 30 minutos. As entrevistas foram transcritas pela pesquisadora e, posteriormente, submetidas à Análise de Conteúdo (BARDIN, 2016), em três etapas: pré-análise, com leitura das transcriçôes, edição do texto e agrupamento do material coletado em 13 categorias iniciais; exploração dos dados para identificação das ideias centrais, com reagrupamento dos conteúdos, configurando 56 problemas éticos iniciais; tratamento dos resultados, inferência e interpretação, desvelando-se uma importante dimensão política nos problemas éticos levantados, reconfigurados em 32 problemas e seis categorias.

\section{Resultados}

Desvelou-se uma concepção hegemônica de ética restrita ao deontológico na identificação dos problemas éticos pelos profissionais da SB, como: quebra de sigilo, privacidade, precariedade nas condiçôes materiais de trabalho, processos éticos e jurídicos que envolvem a responsabilidade civil. A partir dos deveres formalmente prescritos pelos códigos de ética profissionais, limita-se o debate da moralidade às relaçôes contratuais profissional-paciente na esteia do modelo biomédico, no qual a racionalidade instrumental é seu principal elemento. Para além desta concepção de moralidade, foram também considerados os problemas da APS de caráter técnico, administrativo ou estrutural, responsáveis por desencadear conflitos morais. Oriundos dos arranjos singulares do funcionamento da APS e associados a processos macroestruturais transversais à assistência, questôes materiais, financeiras, relacionais e organizacionais apresentaram uma dimensão ética e também política do trabalho em saúde, visto que influenciam modos de viver, trabalhar e produzir cuidados. Como são pouco nítidos os limites de transformação destes problemas cotidianos em problemas éticos, normalmente permanecem na invisibilidade. Seguindo esta compreensão, os problemas foram denominados ético-políticos e apresentados no quadro abaixo. 
Quadro 1. Problemas éticos vivenciados por profissionais da Saúde Bucal na Atenção Primária à Saúde com exemplos de falas das entrevistas, agrupados por categorias

\section{ACESSO AO TRATAMENTO EM SAÚDE BUCAL: OFERTA, DEMANDA E ACOLHIMENTO}

1. Dificuldades para finalização dos tratamentos em saúde bucal. "geralmente são os homens que trabalham, tu dás declaração de comparecimento, porque não vai dar atestado toda vida, mas chega uma hora que eles dizem, "não posso mais porque o meu chefe disse: o dentista ou o trabalho" CD4/ "tem vários problemas, da fila, tem que chegar as 4 horas da manhã" ASB4/ "eles vem resolver aquilo que está machucando, que incomoda e eles não vem mais, mais por medo, outros visam só o estético" TSB1.

2. O acolhimento dos usuários que buscam atendimento odontológico náo segue o preconizado pela ESF.

"passa pelo balcão, elas é que fazem a triagem, mas elas não sabem fazer a triagem da odonto" CD4/ "é a porta de entrada de tudo, está no papel, mas a gente tem dois tipos de acolhimento: o médico e o odontológico" CD2/ "ela faz uma recepção não é acolhimento, não é tão bom como eu acho que deveria ser" CD5.

3. Insuficiência de profissionais para cobertura das áreas. "não é suficiente, o ideal seria ter mais uma equipe para ter o atendimento redondinho" TSB2/ "se tivesse o número de profissionais proporcional à população que é atendida, teria mais resolutividade" CD1.

4. Dificuldades no atendimento de urgência odontológica.

"a conduta quanto às urgências, tem problema, tem profissional que parte só para a medicação, deixa um pouco a desejar" ASB2/ "nem todos os casos realmente são urgência, o critério do que é uma urgência ou não, muitas vezes o paciente quer ouvir do próprio profissional" CD1.

5. Ausência/ insuficiência de TSB para potencializar as atividades individuais e coletivas de promoção à saúde bucal.

"quando tinha uma atividade mais continuada, uma orientação de higiene bucal na cadeira, a gente conseguia fazer um tratamento completado com mais frequência. A dentista mesmo sozinha ela está fazendo a promoçâo nas creches (...), quando eu estava na área eram quase 500 crianças por semestre” TSB1.

6. Ausência ou insuficiência de ASB para desenvolvimento de atividades preventivas e clínicas. "talvez a falta de profissionais auxiliares para potencializar mais essas açóes (preventivas)" $\mathrm{CD} 1 /$ "eu não tenho auxiliar, este é outro problema ético que eu não levantei, estou a 3 meses sem" CD2. 
7. Dificuldade na realização das açôes preventivas devido a problemas nas relaçóes intersetoriais saúde-educação.

“o PSE também é furado, tinha que ter o pessoal da saúde integrado com o pessoal da educação para realmente funcionar (...), o TSB colaborando na escovação supervisionada nas escolas e nas creches, não tem nenhum" CD2.

\section{RECURSOS PARA VISITA DOMICILIAR}

8. Dificuldades técnicas e estruturais para as ESB realizarem visitas domiciliares.

“a limitação de procedimentos, já que não é possível fazer procedimento mais complexo no domicílio, por não ter todo o equipamento necessário, o trajeto para essas residências, muitas vezes através de ruas que não são asfaltadas" CD1.

9. Potencial de ação conjunta ESB-EqSF diminuído.

"é muito difícil o CD se deslocar do consultório, havendo demanda, havendo necessidade dos pacientes sobre a agenda dele... A médica localizou a necessidade, ela convida a gente e nós iremos, a gente ainda não é modalidade II, a gente não tem TSB” CD2.

\section{RELAÇÓES COM OS USUÁRIOS: PRECONCEITOS E DISCRIMINAÇÃO}

10. Violência vivenciada no trabalho.

"infelizmente a violência bate na nossa porta vez ou outra (...) a gente teve um problema com um paciente usuário de droga, como ele não teve acolhimento ele não compreendeu e quando eu fui buscar o prontuário dele de papel, ele veio com bastante agressividade pra cima de mim, entrou na minha sala, pegou uma caneta bic que estava na minha mesa e falou, eu podia te matar com isso, e botou para perto do meu pescoço" CD2.

11. Profissionais da ESB e/ou da UBS discriminam os usuários.

"soro-positivo a gente atende, só que geralmente eu coloco no fim para depois a gente esterilizar tudo" CD4/ "o balcão é muito responsável por chegar e já dizer no médico, dentista ou enfermeira, fulando já está aí, fazendo bafão, bem atacado... daí a pessoa quando chama, faz com o pé atrás, eu já sou vacinada” CD4.

12. Profissionais da ESB testemunham discriminação entre usuários.

"a gente também atende a penitenciária agrícola, eles estão em final de pena, muitos deles fazem trabalho para a prefeitura, manutenção no nosso posto de saúde, na creche, mas na hora que eles vão ser atendidos por nós a comunidade solicita que eles sejam algemados" CD2.

continua.. 
13. Profissionais da saúde bucal entendem que os usuários apresentam problemas cognitivos relacionados à vulneração social.

"sabe quando você fala e a pessoa te olha, parece que você está falando inglês, aqui as pessoas conseguem entender" CD5/ "a comunidade é bem complicada, não sei se chega a ser um problema ético, mas é da comunidade, da compreensão sabe, às vezes a gente enfrenta problema no atendimento, o paciente não entender que não dá para extrair assim infeccionado, dos lugares que eu já trabalhei aqui eu acho que é mais complicado, no entendimento e na comunicação" CD6.

GESTÁO DA APS: QUESTÓES TÉCNICAS E ESTRUTURAIS NO ATENDIMENTO À SAÚDE BUCAL

14. Insuficiência de condiçôes materiais para a integralidade do cuidado "problema no equipamento, falta de material..." ASB3/ "questóes de limitação de procedimentos inerentes à atenção básica, por exemplo, uma restauração que a indicação correta seria uma restauração em bloco, tem essa limitação" CD1.

15. A estrutura física dos consultórios odontológicos dificulta o trabalho em equipe e facilita doenças do trabalho à equipe auxiliar.

"falta de ergonomia no consultório, a gente náo tem espaço para auxiliar... podendo causar dor ou doença por repetição ou por posição errada ao longo do tempo, isto é uma coisa que falta muito na prefeitura e nenhum consultório segue este padrão” TSB1.

16. Profissionais apontam problemas na conduta clínica (técnica), no compromisso e envolvimento do CD.

“já trabalhei em lugares com bastante dentistas, tem bastante divergência em conduta (...) eles realmente não são resolutivos, eles dão umas enroladas" $\mathrm{CD} 2 /$ "o trabalho público hoje em dia se faz muito curativo e esta forma de trabalhar eu sou contra" CD7.

17. Desvalorização do serviço público e falta de corresponsabilização do usuário.

"a nossa auxiliar vem de um trabalho anteriormente no sistema privado, então ela não tem qualquer tipo de preguiça de fazer as coisas" CD1/ "o SUS ele é feito para ser exemplo, o SUS não deveria ser um sistemazinho, o postinho" CD2/ "já trabalhei com profissional que colocou prótese removível e cobrou em consultório do SUS" TSB1/ "a falta aqui na UBS, talvez porque não seja tão difícil conseguir uma ficha, as pessoas não valorizam” TSB2.

18. Diminuição ou ausência de atendimento odontológico de urgência nas UPAs.

“até início do mês a gente tinha acesso à UPA, agora eles vão tirar os dentistas do dia, vão ficar só os dentistas da noite e do final de semana, e os postos de saúde na situação em que se encontram não tem condiçôes de atender esta demanda que iria para as UPAs" TSB1/ "a gestão não consegue compreender a necessidade da urgência odontológica mesmo nas UPAs... é subestimada e é desumano" CD2. 
19. Dificuldades no sistema de exames radiográficos.

"é um grande fracasso, hoje a prefeitura oferece para o paciente exames periapicais, com um tempo quantitativo pequeno, de uma forma onde eles conseguem economizar com a gente, eu já tive duas visóes: uma de não ter o $\mathrm{Rx}$ no consultório, onde tivesse uma central radiológica que não expusesse a gente a alguns agentes. Hoje, mesmo sabendo que é uma tecnologia cara, seria essencial que isso fosse oferecido na APS, tem que oferecer qualidade, qualquer consultório de esquina tem pelo menos uma radiografia periapical para oferecer" CD2.

20. Condiçóes de trabalho precarizadas.

"eu tive problema com o RX, as paredes não são baritadas, a porta não é chumbada, eu questionei isso e o coordenador veio me dizer que eu era uma simples auxiliar que eu não tinha capacidade para discutir isso com ele" ASB2.

REDE DE ATENÇÃO ÀSAÚDE: RELAÇÃO ATENÇÃO PRIMÁRIA E SECUNDÁRIA

21. Demora para se conseguir o tratamento especializado em saúde bucal.

"consulta especializada... quando chega a sair, talvez não tenha mais interesse, resolveu por fora" TSB2.

22. Problemas estruturais para alocar adequadamente os profissionais no CEO

"o CEO não tem uma estrutura que caiba todos os profissionais que são especialistas, então, a sensação que passa é que é uma enrolação" CD5/ "o problema é que aqui no CEO a periodontista náo é periodontista" CD7.

23. Dificuldades na referência devido ao excesso de exigências administrativo-burocráticas ao acesso aos serviços de média complexidade em saúde bucal.

“às vezes faltou um detalhe, questóes que a própria regulação poderia presumir e esses exames são devolvidos por esses detalhes, talvez a minha queixa em relação ao CEO seja burocrática" CD1.

24. Falta de transparência na fila de espera pelos serviços de média complexidade em saúde bucal.

"como o CEO não tem regulação via SISREG, não tem transparência na fila do atendimento" CD2.

RELAÇÓES INTERPESSOAIS INTRA E INTEREQUIPES

25. Dificuldades dos profissionais de saúde bucal para realizar trabalho em equipe.

"nós não temos muito entrosamento, falta um pouco mais de trabalho em equipe, tem pessoas que tem dificuldade na mudança” ASB2. 
26. Subestimação e desvio de função de TSB para ASB.

"hoje eu posso dizer que TSB na prefeitura já tem o seu espaço, porque quando eu entrei era uma profissão nova e a gente não tinha especificaçôes de serviço, e a gente foi rebaixado para auxiliar, mas com o passar dos anos isto foi mudando com a mentalidade dos próprios dentistas, não a rede em si que visa o técnico como uma pessoa de artifício, um curinga, para ajudar no auxílio das atividades" TSB 1.

27. Engajamento dos profissionais à ESF está relacionado à formação específica para a área. “existe muita diferença quando há especialista em saúde da família, porque eles interagem, há muito mais interconsulta, agora quando o médico não tem esta especialidade, ele não vê a odontologia como complemento de tratamento, ele nem lembra” TSB 1.

28. Subestimação do ASB. Engajamento dos profissionais à ESF está relacionado à formação específica para a área.

"Uma vez que eu questionei o graal cirúrgico e questionei a seladora, de chegar a fazer piada, como se no serviço público não fosse necessário, só no consultório particular” ASB2.

29. Falta de união dos trabalhadores para maior valorização no trabalho na APS e em saúde bucal.

"a gente não se une como categoria, os médicos também não, a gente acredita que isso não existe" CD2.

30. Incompreensão da atuação do CD para além da ação curativa e como parte da ESF. "outros colegas da equipe não entendem o trabalho da odonto, dentista só é bom se estiver sentado na cadeira, com a broca" CD6.

31. Profissionais criticam os (as) colegas CD.

"percebi situaçôes em relação a outros colegas da equipe, assim, de falar, fica falando por trás” CD6.

32. Falta de apoio da gestão para resolução de problemas éticos vivenciados. "Já teve caso de paciente processar médico da minha equipe. $\mathrm{Na}$ discussão de equipe a gente escutou, parece que ele fez tudo que era possível, mas que as pessoas queriam achar algum culpado e acabou que envolvendo ele, mas ele ficou muito abalado, a equipe toda ficou muito abalada, uma coisa bem complicada, porque a gente não sente muito suporte da prefeitura nesses casos, meio que realmente fica por conta da pessoa" CD5.

Legenda: APS - Atenção Primária à Saúde; ESF - Estratégia de Saúde da Família; UBS - Unidade Básica de Saúde; ESB - Equipe de Saúde Bucal; EqSF - Equipe de Saúde da Família; ASB - Auxiliar de Saúde Bucal; TSB - Técnico de Saúde Bucal; CD - Cirurgião-dentista; CEO - Centro de Especialidades Odontológicas; UPA - Unidade de Pronto-Atendimento. 


\section{Discussão}

O contrato do tipo liberal pautado no utilitarismo hedonista e no ideário biopolítico do indivíduo-empresa hegemoniza a intermediação das relações humanas nas sociedades capitalistas modernas, dificultando a reflexividade sobre a ação cooperativa e comunicativa em saúde, especialmente necessária no setor público por seu compromisso social. Contrapondo-se a este contratualismo, o modelo do cuidado humanizado da Saúde da Família propóe transformar a qualidade das relaçôes interprofissionais/ de gestáo e entre profissionais-usuários, aumentando o grau de corresponsabilidade e os vínculos de solidariedade destes diferentes atores. Um novo modus operandi pautado no valor intrínseco da saúde e no valor de uso do trabalho que solicita novos posicionamentos ético-políticos na tomada de decisão e implementação de açôes, com base na troca dialógica de saberes e cogestão, especialmente em contextos de vulneração socioeconômica (GOMES; RAMOS, 2015). A moralidade deontológica, nestes casos, precisa ser superada, conduzindo a uma abordagem qualificada dos problemas éticos.

A Bioética Clínica Amplificada, por se referir a práticas concretas envolvidas em conflitos morais entre profissional-equipes-usuário-comunidade-sociedade, constitui um novo pragmatismo que unifica teoria e prática, experiência e reflexão. $\mathrm{Na}$ vivência de casos concretos como práticas assistenciais e em cenários institucionais, o conhecimento dos fatos sempre pressupõe uma estimativa dos valores envolvidos, tornando-os inseparáveis. Assim, os valores são percebidos como reais e necessários ao estabelecimento do vínculo entre o conhecer e o agir, conectando-se ideiasfatos-valores-práxis. Buscando-se uma análise dialética do problema por meio de um enfoque interdisciplinar e uma argumentação deliberativa, destacam-se três aspectos: um fato real constituído de conflitos morais na inter-relação profissionalusuário; uma competência ética específica por parte do agente moral; e um contexto sociológico e antropológico de pluralismo moral (sociedades democráticas). Mesmo vivenciando modernamente o "colapso do consenso", busca-se algum tipo de relação pautada na comunicação e na análise crítica dos fenômenos morais através da problematizaçáo, para se chegar a acordos práticos. Para tanto, torna-se central desvelar o lugar da conflituosidade nas práticas em saúde, intrínseca às relaçôes humanas e manifestada como relaçóes políticas (SCHRAMM, 2015). 
Na APS, percebe-se a porta de entrada exclusiva da SB como um problema éticopolítico do acolhimento, pois arrisca a perda da integralidade do cuidado, do trabalho ampliado interequipes e de um fluxograma que atenda às reais demandas do usuário. A unificação no acolhimento acontece mais frequentemente nos serviços voltados a grupos, entretanto, geralmente como encaminhamento automático, sem planejamento e ação conjunta das ESB-Equipe de Saúde da Família (EqSF). Além disto, este acolhimento perde-se muito como trabalho de recepção ou triagem administrativa, na disposição de vagas de demanda ou urgência e acesso ao profissional, deixando de significar uma qualificação do acesso (CARNUT et al., 2017), com reorganização do processo de trabalho para um cuidado ampliado, com escuta e diálogo qualificado e resolutivo - fora do ambiente operatório (GRAFF; TOASSI, 2018).

A gestão dos problemas relacionados à alta demanda e acesso precário, que significam filas de espera e horários dificultadores ao agendamento - na APS e na atenção secundária -, devem passar por uma política de melhora constante do acolhimento e da rede de urgências (MARTINS et al., 2016; GOMIDE et al., 2018). Apesar de a cobertura do acolhimento nos modelos que seguem majoritária ou exclusivamente a Estratégia encontrar-se acima de 50\% na média da realidade brasileira e o PMAQ atestar altas coberturas no atendimento por cinco ou mais dias na semana, em dois ou mais turnos, outros indicadores atestam baixas coberturas potenciais, a exemplo de atendimento nos finais de semana, horários noturnos e de almoço, falta de profissionais e o excesso de usuários por área adstrita (POÇAS; FREITAS; DUARTE, 2017; THUROW; CASTILHOS; COSTA, 2015).

Problemas complexos de operacionalização da interface AP-urgências odontológicas são acentuados pela ausência deste serviço nas Unidades de Pronto Atendimento (UPA) ou pelo baixo aprimoramento, expansão e adequação onde existem, como sugerem as diretrizes da PNAB (POÇAS; FREITAS; DUARTE, 2017). Especialmente desde 2016, verifica-se uma diminuição dessa cobertura nas UPAs, seguindo um processo de alinhamento das administraçóes municipais às políticas federais neoliberais de austeridade do Estado (BRAZIL, 2019). À escusa de financiamento insuficiente, força-se a diminuição dos horários e impossibilita-se a utopia desta cobertura onde não existe, desconsiderando-se que a população socioeconomicamente vulnerada é a mais acometida pela dor de dente. Percebida como uma das piores sensaçôes e fonte de grande sofrimento, a odontalgia tem impacto negativo na produção e na qualidade de vida da população (LUCAS et al, 2014). Comunica-se com o absenteísmo no 
trabalho em via de mão dupla: quando este acontece pelo sofrimento da dor e quando inviabiliza a continuidade ao tratamento como determinante macroestrutural, na prioridade da manutenção do emprego.

A carência do trabalho técnico, que equivale à razão de 7 TSB para cada 100 dentistas (AGUIAR; FRAZÃO, 2016), ocasiona problemas éticos em variadas esferas da produçáo, com diminuição do impacto na melhoria dos indicadores em SB na população. A sua inclusão ao serviço emperra na formação clínica não inclusiva do trabalho em equipe a quatro ou seis mãos; na ausência de calibração para procedimentos de acolhimento e urgência; na baixa construçáo de vínculos solidários e aperfeiçoamento das redes de atenção; e no desvio de suas funçôes pelas gerências, transformando-os em "curingas" no processo produtivo, não diferenciando suas funções das competências do auxiliar (WARMILING et al., 2016) e diminuindo substancialmente uma potencial comunicabilidade ativa e construção de projetos comuns. O seu trabalho de promoção à saúde na clínica potencializa a conclusão do tratamento (THUROW; CASTILHOS; COSTA, 2015), desconstruindo a busca pontual por soluções a problemas estéticos ou dolorosos. A sua capacidade de implicação através da sensibilização e diálogo, além de melhorar o acesso, atua na diminuição do medo e das incertezas que, frequentemente, envolvem a assistência odontológica.

Apesar de avanços na relação intersubjetiva entre os diferentes profissionais da ESB, permanecem conflitos importantes, especialmente na relação do CD com o corpo auxiliar, como: ausência de entrosamento e afetividade; excesso de individualismo; preconceito, inferiorização e ridicularização do auxiliar; problemas na comunicação inter-CD e entre profissionais e coordenação. A escassa comunicação e padronização de procedimentos entre os $\mathrm{CD}$, com acentuada divergência de condutas, incluindo os procedimentos de urgência, diminuem a resolutividade. Especialmente quando amplificados pela ausência ou subestimação do trabalho em equipe, falta de vontade e insuficiente comprometimento profissional e gerencial com o usuário e o sistema de saúde. Pressupóe-se uma tendência à persistência de relaçôes hierarquizadas e corporativas pautada na "autoridade" clínico-operatória do CD (ZOBOLI; FORTES, 2004), refletida na baixa descentralização do trabalho clínico, geradora de insatisfação, limitadora de potencialidades e do protagonismo técnico.

$\mathrm{O}$ ideal profissional de atuação exclusiva do $\mathrm{CD}$ na cadeira, voltada à cura no ambiente individualizado e hermético do consultório e a partir da ideação do 
"cirurgião dentário", é reforçado também por gestores e profissionais de outras áreas da saúde, que se contrapóem, na prática, a um trabalho cooperativo interpessoal e intersubjetivo - com produção do comum (FONSECA et al., 2016; FARIAS et al., 2018; LIMA et al., 2017). Diferentemente de outras pesquisas, as condiçôes de trabalho no SUS (salários e estabilidade) não ficam evidenciadas como fonte maior de valorização e comprometimento ético-político do profissional (CARNUT et al., 2017). Adquire maior importância a construção de nova subjetividade de engajamento-disposição dos profissionais e gerências dentro de novos paradigmas de ação, especialmente através do investimento na pós-graduação em Saúde da Família - residências ou especializaçóes.

Esta formação dirigida à saúde da família estaria voltada a superar problemas ainda presentes na formação, como o insuficiente treinamento no enfoque da Saúde Bucal Coletiva, sobre o papel da APS e do contexto social, também suplantando o aprendizado prático que acaba acontecendo no serviço, na experiência individualcoletiva (SCHERER; SCHERER, 2015). Como essa pós-graduação problematiza os problemas cotidianos a partir do próprio processo de trabalho, amplia-se a disposição do profissional à transformação de práticas e relaçôes. Prioriza-se valores coletivos, relações solidárias e democrático-cooperativas, em que o usuário aparece como fim, primeiro e último do trabalho em saúde, buscando-se superar incompreensôes na reorganização do processo de trabalho; hierarquizaçôes de poder e competitividade associados aos processos de mercantilização da saúde; além da desconexão existente com o trabalho voltado ao conjunto da sociedade (FONSECA et al., 2016).

O funcionamento dos procedimentos radiológicos de forma centralizada é reconhecido como obsoleto e insuficiente, significando tempo de espera relativamente grande do usuário por um serviço limitado, normalmente, a radiografias periapicais e, em alguns casos, com precarização das condiçóes de trabalho. Mesmo considerado um modelo ultrapassado pela odontologia de mercado, este padrão de produção acaba naturalizado para o serviço público, subsumido a problemas estruturais, como insuficiente financiamento, e refletindo falta de debate coletivo sobre a real viabilidade do modelo de mercado como referencial de boas práticas, também para o serviço público-estatal. Uma pauta invizibilizada por falhas no modelo formador e nas pesquisas científicas voltadas à qualificação do serviço radiológico no SUS; ausência de mobilização da população na abertura de processos de responsabilização 
civil aos profissionais do SUS; participação em fóruns democráticos de controle social; e des-responsabilização do próprio profissional para com a melhoria desse serviço.

Apesar dos avanços na oferta de atenção especializada em SB, chegando-se à conclusão do tratamento para a maioria da demanda em terapêutica especializada (aos que deram entrada), com finalizaçáo dos procedimentos restauradores pela clínica da AP na mesma proporção (SALIBA et al., 2013), alguns problemas funcionam como obstáculos ao avanço da qualidade na relação APS-CEO: demora e falta de transparência na fila de espera; estruturas aquém das necessidades que não comportam todos os profissionais especialistas contratados; e problemas burocráticos de protocolos de encaminhamento e adesão a estes protocolos. Aponta-se a necessidade de revisão dos critérios de implantação dos CEO (SILVA; GOTTEMS, 2017), com avaliação continuada da relação APS-CEO.

As limitaçóes no atendimento odontológico domiciliar, face às dificuldades de ação clínico-cirúrgica, e no acesso do odontomóvel, associadas à ausência do TSB para o trabalho de promoção à saúde, transforma-a em ação secundária, como apoio, em cooperação ou indicação da EqSF (NORO TORQUATO, 2015). Apesar de uma relação de respeito entre as ESB e EqSF, poucas açóes de planejamento e execução são desenvolvidas conjuntamente, ainda não existindo adequada articulação intersubjetiva e interprofissional interequipes (BARROS et al., 2016).

No desenvolvimento de açôes coletivas de prevenção e promoção nas escolas, além da ausência de trabalho técnico-auxiliar, configura-se fonte de problemas éticopolíticos a falta de comunicação e cooperação do setor educação com saúde, em especial, no desenvolvimento do Programa de Educação pelo Trabalho para a Saúde - PET-Saúde da Família. Esta ação intersetorial torna-se meramente burocrática quando não há esforços para construção de uma gestão colegiada (NORO; TORQUATO, 2015; MADRUGA et al., 2015). Além disto, torna-se insatisfatória pela pouca inclusão de grupos populacionais vulnerados, ainda pouco observando: determinantes socioeconômicos e dados epidemiológicos; referenciais pedagógicos problematizadores e dialógico-comunicativos; e práticas de empoderamento e autonomia (MATOS; CRISTINO; ALMEIDA, 2016).

Preconceitos e estigmas em relação aos usuários acontecem veladamente a pacientes com doenças transmissíveis, como o HIV, levando o paciente a ser "deixado por último em função da esterilizaçấo dos instrumentais". Quando ocorrem na recepção da UBS, afetam os processos de acolhimento e humanização. 
Atitudes preconceituosas também por parte dos usuários para com outros usuários (como os oriundos do sistema presidiário) atestam estigma social preconcebido sob uma biopolítica do medo e "segurança", segregadora e discriminatória. No mesmo sentido, a violência interpessoal que atropela profissionais na clínica é relacionada a problemas no acesso e acolhimento, tanto quanto a problemas molares transversais, como pobreza e uso de drogas. Trata-se de uma demanda ainda pouco debatida pela responsabilidade difusa associada, sendo esta relegada a entes morais e lugares não nominados do sistema; a concepçôes de relação contratual profissional-paciente alicerçadas na odontologia de mercado; e em uma sub-cidadania socialmente introjectada ao usuário do SUS - que nega direitos e qualidade de atençâo por seu (não) poder de compra. Assim, culpabiliza-se o paciente pela violência, anulando conflitos morais e, por conseguinte, a reflexividade sobre os processos de trabalho, que engloba os determinantes socioeconômicos e culturais.

Problemas ergonômicos no trabalho auxiliar e falta de material-instrumental aparecem como contextos adversos, buscando-se alternativas para manutenção da eficiência clínica (SCHERER; SCHERER, 2015). Desvelam-se como fonte de sofrimento moral, a limitação de procedimentos ou serviços não oferecidos no SUS e a não conclusão de tratamento associada a fatores socioeconômicos, vulneração social e cultural do usuário, incluindo dificuldades cognitivas. A impotência na soluçáo de casos e a falta de protagonismo no atendimento, explicativa da ocorrência de parte dos problemas éticos na APS, é detectada como vulneração programática dos profissionais (JUNGES; BARBIANI; ZOBOLI, 2018). Assim, apontam-se vertentes interconectadas de responsabilização e problematização éticopolítica, associadas à transversalidade na clínica da (des) informação midiática; (des) estímulo à participação democrática (SIQUEIRA-BATISTA et al., 2015); ideologias e biopolíticas dominantes, para além dos problemas vinculados diretamente ao sistema de saúde (VIDAL et al., 2014).

A quase absolutização do pragmatismo e de valores instrumentais (individuais e paternalistas) na relação profissional-paciente e serviços de saúde-usuários, coloca em questão a ética no setor público, desvelando o comportamento e a responsabilidade social do Estado, usuários e profissionais, para além da velha dicotomia do bem/ mal, certo/errado. A ética adquire identidade pública, não sendo considerada apenas "uma questáo de consciência a ser resolvida na esfera privada ou particular, de foro individual e exclusivamente íntimo". Na contemporaneidade, a hegemonia global 
do setor financeiro, sustentada em regras democráticas fracas e no individualismo hedonista fragmentador, acentua um relativismo moral que sacrifica os direitos sociais como a saúde. No atual contexto brasileiro, acentua-se a face neoliberal do capitalismo que desnuda os interesses fratricidas do capital sobre o trabalho e sobre a solidariedade como valor necessário à cooperação, comprometimento e participação. A profunda desigualdade socioeconômica e cultural confere-se como fator patógeno das doenças "modernas". Contrasta-se uma medicina tecnicamente avançada e cara com a realidade de milhões de vulnerados sem acesso, transformando a (bio) ética em instrumento de libertação e intervenção cidadã, com centralidade para a organização e participação democrática em deliberação ético-política (GARRAFA, 2004).

$\mathrm{Na}$ superação do desequilíbrio entre ser humano e natureza, e entre os próprios seres humanos, faz-se necessária uma democracia ampliada, participação direta e discriminação positiva, contrária à loteria determinada pela posição de classe e estamento social, com investimento deliberado para mudanças na organização social e no nível da solidariedade compactuada. Seguindo o princípio de justiça dos sistemas de saúde solidaristas, as liberdades e decisóes individuais podem ser restringidas na priorizaçáo de investimentos para o bem comum e para o aumento da qualidade de vida geral da população, não tanto como uma oposição entre interesses, mas como complementaridade. A ética das escolhas públicas questiona em que medida o Estado pode e como deve intervir para construir uma relaçáo de qualidade na atenção em saúde, o que significa não somente a melhora dos serviços e processos de trabalho, mas a compreensão do papel dos determinantes sociais que influenciam as políticas públicas e as escolhas dos indivíduos copartícipes enquanto sujeitos sociais. O foco da (bio) ética é amplificado na dimensão coletiva e cooperativa nas relaçôes sociais e de poder, e no controle coletivo da economia e dos processo de trabalho pelos próprios trabalhadores (BERLINGUER, 2015; GARRAFA, 2004).

Tratando-se de planejamento, implementação e avaliação moral de programas e políticas sanitárias de governo e de Estado, não há obrigação de resposta concreta a alguém ou de alguém individualizado e identificável. Trata-se de um outro "indeterminado", de escolhas de agentes morais que atuam em nome do bem público (suas deliberaçôes individuais ou coletivas e suas consequências), um sujeito impessoal (Estado, deliberação coletiva, equipe e rede de saúde) e sem destinatário identificável - população, objeto principal de atuação da saúde coletiva. É considerada relativa a autonomia do indivíduo "paciente" desta ação, 
visto que está vinculada à competência de discernimento do sujeito, conhecimento de direitos, nível de participação coletiva e realidade democrática que a permeia (incluindo ação de meios de comunicação, informação e fundamentação religiosa). A ética da responsabilidade individual, assim, torna-se limitada e insuficiente, pois a responsabilizaçáo vai depender de condiçóes como: o grau de liberdade de cada pessoa envolvida, seu estágio de desenvolvimento moral e maturidade psicológica, seu poder efetivo, seu nível de engajamento e participação ético-política, conhecimentos epidemiológicos, socioeconômicos, do contexto e das situaçôes concretas de ação no território. O principio da proteção, alicerçado no consequencialismo/utilitarismo e direitos humanos, valorada a saúde como bem intrínseco e direito individual e social, supre a lacuna da responsabilização individual dos agentes morais difusos, como integração entre responsabilidade moral e eficácia pragmática, acrescendo a Bioética Clínica Amplificada (SCHRAMM, 2004).

\section{Conclusão}

Este levantamento de problemas éticos vividos no âmbito da SB da APS corrobora a assertiva de que tais problemas estão naturalizados nas relaçóes e circunstâncias comuns e cotidianas da atenção à saúde, não pautados necessariamente em situaçôes limite ou dilemáticas como em outros níveis da rede de atenção à saúde. A construção da clínica ampliada e não hierarquizada, que quebra o tradicional modelo do profissionalismo, não toma como centralidade as especifidades profissionais, mas as necessidades de saúde dos usuários e território, requerendo a participação comprometida e engajada de todos os componentes da SB.

Aponta-se a existência de uma prática em SB mais próxima de açóes que compatibilizam a atuação técnica com a luta pela melhoria da vida social, potencializando, concomitantemente, uma melhora dos processos de trabalho na clínica a partir de um profissional reflexivo e politicamente mais comprometido. Com isto, destaca-se a necessidade de a formação voltar-se ao trabalho clínico em equipe, vinculado aos preceitos humanizadores e cidadãos da ESF, somados a um empreendedorismo solidário e a uma dialogicidade-comunicação para a cogestão.

Os resultados desta pesquisa podem ajudar a fomentar o debate coletivo sobre os problemas éticos na SB. Especialmente quando corrobora trabalhos anteriores (ZOBOLI; FORTES, 2004; GUEDERT; GROSSEMAN, 2011) que sugerem 
a estrutura dos serviços como não potencializadora de apoio, nem conformadora de espaços voltados à percepção, análise e solução destes problemas, mesmo constituindo-se em importante fator causal. Faz-se necessário construir fóruns ou espaços de debate da ética na APS em separado do debate bioético nos ambientes especializados ou hospitalares.

A superação do conflito entre um Estado austero e mínimo e a manutenção de um sistema de saúde solidarista, em uma sociedade desigual como a brasileira, mantém no centro do debate da Bioética Clínica Amplificada a questão da ética pública, com democracia participativa e garantia da saúde como valor e direito humano; e do conceito de proteção aplicado ao planejamento, efetivação e avaliação das políticas públicas. Nesse sentido, precisam ser cotidianamente considerados como desafio, o nível de coesão, participação cidadã e solidariedade pautados em conhecimentos e valores basilares do comprometimento pessoal e coletivo dos trabalhadores da saúde, com a equipe e projetos democráticos de cogestão e deliberação ético-política. ${ }^{1}$

\section{Referências}

AGUIAR, D. M. L.; FRAZÃO, P. A insuficiência da política pública para inclusão do técnico em saúde bucal na atenção primária no Brasil. In: CHAVES, S. C. L. (Org.). Política de saúde bucal no Brasil: teoria e prática. Salvador: EDUFBA, 2016, p. 297-318.

AMORIM, A. G.; SOUZA, E. C. F. Problemas éticos vivenciados por dentistas: dialogando com a bioética para ampliar o olhar sobre o cotidiano da prática profissional. Ciênc. Saúde Coletiva, v. 15, n. 3, p. 869-878, 2010.

AUSTRAGÉSILO, S. C. et al. A Interface entre a Atenção Primária e os Serviços Odontológicos de Urgência (SOU) no SUS: a interface entre níveis de atenção em saúde bucal. Ciênc. Saúde Coletiva, v. 20, n. 10, p. 3111-3120, 2015.

BARDIN, L. Análise de conteúdo. São Paulo: Edições 70: Almedina Brasil, 2016.

BARROS, S. G. et al. Atenção primária e saúde bucal: as evidências de sua implementação no Brasil. In: CHAVES, S. C. L. (Org.). Politica de saúde bucal no Brasil: teoria e prática. Salvador: EDUFBA, 2016, p. 173-201.

BERLINGUER, G. Bioética Cotidiana. Brasília: Editora Universidade de Brasília, 2015.

BRASIL. Ministério da Saúde. Brasil Sorridente. Portal do Departamento de Atenção Básica. Disponível em: <http://dab.saude.gov.br/portaldab/ape_brasil_sorridente.php>. Acesso em: 12 jan. 2018. 
BRAZIL ENTERS THE BOLSONARO ZONE (Editorial). The Lancet Global Health, v. 7, Feb., 2019. Disponível em: <https://www.thelancet.com/action/showPdf?pii=S2214109X\%2819\%2930002-6>. Acesso em: 22 Jan. 2019.

CAMPOS, G. W. S. Clínica e saúde coletiva compartilhadas: teoria paidéia e reformulação ampliada do trabalho em saúde. In: CAMPOS, G. W. S. (Org.). Tratado de Saúde Coletiva. São Paulo: Hucitec, 2013, p. 39-78.

CANGUSSU, M. C.; PASSOS-SOARES, J.; CABRAL, M. B. Necessidades e problemas de saúde bucal no Brasil e tendências para as políticas de saúde. In: CHAVES, S. C. L. (Org.). Politica de saúde bucal no Brasil: teoria e prática. Salvador: EDUFBA, 2016, p. 47-76.

CARNUT, L. et al. Principais desafios do acolhimento na prática da atenção à saúde bucal: subsídios iniciais para uma crítica. Rev. ABENO, v. 17, n. 4, p. 46-62, 2017.

COSTA, S. M. et al. Práticas de trabalho no âmbito coletivo: profissionais da equipe Saúde da Família. Cad. Saúde Coletiva, v. 22, n. 3, p. 292-299, 2014.

FARIAS, D. N. et al. Interdisciplinaridade e Interprofissionalidade na Estratégia de Saúde da Família. Trab. Educ. Saúde, v. 16, n. 1, p. 141-162, 2018.

FONSECA, G. S. et al. A clínica do corpo sem boca. Saúde Sociedade, v. 25, n. 4, p. 10391049, 2016.

FORTE, E. C.; PIRES, D. E. P. Enfermeiras na Atenção Básica: entre a satisfação e insatisfação no trabalho. Trab. Educ. Saúde, v. 15, n. 3, p. 709-724, 2017.

FORTES, P. A. C. Ética e saúde. São Paulo: EPU, 2011.

FRAZÃO, P.; NARVAI, P. C. Lei n. 11889/2008: avanço ou retrocesso nas competências do técnico em saúde bucal? Trab. Educ. Saúde, v. 9, n. 1, p. 109-123, 2014.

GARRAFA, V. Reflexão sobre políticas públicas brasileiras de saúde à luz da bioética. In: ZOBOLI, L. E. C. P.; FORTES, P. A. C. (Orgs.). Bioética e saúde pública. 2. ed. São Paulo: São Camilo/Loyola, 2004, p. 49-69.

GOMES, D.; RAMOS, F. R. S. Solidariedade, aliança e comprometimento do profissional da saúde nas práticas do Sistema Único de Saúde (SUS): um debate bioético. Interface. Botucatu, v. 19 , n. 52, p. 9-20, 2015 a.

GOMIDE, M. F. S. et al. A satisfação do usuário com a atenção primária à saúde: uma análise do acesso e acolhimento. Interface. Botucatu, v. 22, n. 65, p. 387-398, 2018.

GRAFF, V. A.; TOASSI, R. F. C. Clínica em saúde bucal como espaço de produção de diálogo, vínculo e subjetividades entre usuários e cirurgiōes-dentistas da Atenção Primária à Saúde. Physis: Revista de Saúde Coletiva. Rio de Janeiro, v. 28, n. 3, e280313, 2018. 
GUEDERT, J. M.; GROSSMAN, S. Abordagem dos Problemas Éticos em Pediatria: Sugestóes Advindas da Prática. Rev. Bras. Ed. Méd., v. 35, n. 3, p. 359-368, 2011.

JUNGES, J. R.; ZOBOLI, E. L. C. P. Bioética e saúde coletiva: convergências epistemológicas. Ciênc. Saúde Coletiva, v. 17, n. 4, p. 1049-1060, 2012.

JUNGES, J. R. et al. Validação da compreensibilidade de um instrumento sobre problemas éticos na atenção primária. Rev. Gaúcha Enferm., v. 35, n. 1, p. 148-156, 2014 a.

JUNGES, J. R. et al. Construção e validação do instrumento "inventário de problemas éticos na atenção primária em saúde”. Rev. Bioética, v. 22, n. 2, p. 309-317, 2014 b.

JUNGES, J. R.; BARBIANI, R.; ZOBOLI E. L. C. P. Vulneração programática como categoria explicativa dos problemas éticos na atenção primária à saúde. Trab. educ. saúde, v. 16, n. 3, p. 935-53, 2018.

LIMA, M. M. et al. Indications of comprehensiveness in the pedagogical relationship: a design to be constructed in nursing education. Rev Esc Enferm USP, v. 51, e03277, 2017.

LUCAS, S. D. et al. Uso de metáforas para expressar a dor de dente: um estudo na área de antropologia da saúde. Ciênc. Saúde Coletiva, v. 19, n. 6, p. 1933-1942, 2014.

MADRUGA, L. M. S. et al. O PET-Saúde da Família e a formação de profissionais da saúde: a percepção de estudantes. Interface. Botucatu, v. 19, n. 1, p. 805-816, 2015.

MARTINS, A. B. et al. Availability of dental treatment is associated with satisfaction derived from Primary Health Care Services accessed by elderly. Rev. Odontol. UNESP, v. 45, n. 6, p. 344-350, 2016.

MATOS, M. S.; CRISTINO, P. S.; ALMEIDA, T. F. Educação em saúde bucal do trabalhador. In: CHAVES, S.C. L. (Org.). Politica de saúde bucal no Brasil: teoria e prática. Salvador: EDUFBA, 2016, p. 273-95.

NORO, L. R. A.; TORQUATO, S. M. Visita domiciliar: estratégia de aproximação à realidade social? Trab. Educ. Saúde, v. 13, n. 1, p. 145-157, 2015.

POÇAS, K. C.; FREITAS, L. R. S.; DUARTE, E. C. Censo de estrutura da Atenção Primária à Saúde no Brasil (2012): estimativas de coberturas potenciais. Epidemiol. Serv. Saúde, v. 26, n. 2, p. 275-284, 2017.

PORTO, D.; GARRAFA, V. A influência da Reforma Sanitária na construção das bioéticas brasileiras. Ciênc. Saúde Coletiva, v. 16, n. 1, p. 719-795, 2011.

SALIBA, N. A. et al. Organização da demanda de um Centro de Especialidades Odontológicas. Rev Odontol UNESP, v. 42, n. 5, p. 317-323, 2013.

SCHERER, C. I.; SCHERER, M. D. A. Avanços e desafios da saúde bucal após uma década de Programa Brasil Sorridente. Rev. Saúde Pública. São Paulo, v. 49, p. 98, 2015. 
SCHRAMM, F. R. A Bioética da Proteção em saúde pública. In: ZOBOLI, L. E. C. P.; FORTES, P. A. C. Bioética e saúde pública. 2. ed. São Paulo: São Camilo:Loyola, 2004, p. 71-84.

SCHRAMM, F. R. Três ensaios de Bioética. Rio de Janeiro: Fiocruz, 2015. 177 páginas.

SIQUEIRA-BATISTA, R. et al. (Bio) ética e Estratégia Saúde da família: mapeando problemas. Saúde Soc. São Paulo, v. 24, n. 1, p. 113-128, 2015.

SILVA, H. E. C.; GOTTEMS, L. B. D. Interface entre a Atenção Primária e a Secundária em odontologia no Sistema Único de Saúde: uma revisão sistemática integrativa. Cien. Saúde Colet., v. 22 , n. 8 , p. $2645-2657,2017$.

THurOW, L. L.; CASTILHOS, E. D.; COSTA, J. S. D. Comparação das práticas odontológicas segundo modelos de atendimento: tradicional e da Saúde da Família, Pelotas-RS, 2012-2013. Epidemiol. Serv. Saúde, v. 24, n. 3, p. 545-550, 2015.

VIDAL, S. V. et al. Problemas bioéticos na Estratégia Saúde da Família: reflexões necessárias. Rev. Bioét., v. 22, n. 2, p. 347-357, 2014.

WARMILING, C. M. et al. Competências de Auxiliares e Técnicos de Saúde Bucal e o vínculo com o Sistema Único de Saúde. Trab. Educ. Saúde, v. 14, n. 2, p. 575-592, 2016.

ZOBOLI, E. L. C. P.; FORTES, A. C. F. Bioética e atenção básica: um perfil dos problemas éticos vividos por enfermeiros e médicos do Programa Saúde da Família, São Paulo, Brasil. Cad. Saúde Pública, v. 20, n. 6, p. 1690-1699, 2004.

ZOBOLI, E. L. C. P. Deliberação: leque de possibilidades para compreender os conflitos de valores na prática clínica da atenção básica. 2010. (Tese) - Escola de Enfermagem da Universidade de São Paulo, São Paulo.

\section{Nota}

${ }^{1}$ D. Gomes trabalhou na concepção e redação do texto. M. Finkler, na redação e revisão crítica do artigo. E. Zoboli, na revisão crítica do artigo. 


\section{Abstract}

\section{Oral health ethical problems in the context of Primary Health Care}

In view of the absence of studies focusing on ethical issues experienced by oral health professionals in the context of Primary Health Care (APS) and as the first stage of adaptation with validation of the Inventory of Ethical Problems in Primary Health Care (IPE-APS) for the oral health, this research aimed to disclose ethical problems that occur in work relationships and in oral care production. Interviews were conducted with dentistry professionals within the Family Health Strategy model, in traditional APS or unique arrangements. Data was collected and qualitatively analyzed in light of an amplified clinical Bioethics and other theoretical frameworks of the Brazilian Social Bioethics. The results revealed 32 ethical-political problems in different spheres: access and reception, management, relationships with users, intra- and interteams relationships, relations among different network levels, and in macro-structural processes, leaving little limits for transforming everyday problems into ethical ones. These problems, most of which are of technical, administrative or structural nature, involving material, financial and organizational issues, have an ethical and a political dimension, as they influence the ways of living, working and producing care.

> Keywords: dentistry; oral health; primary health care; bioethics; ethics. 